\title{
Anomalous Left Coronary Artery from the Pulmonary Artery: The Role of Multimodal Imaging-A Case Report
}

\author{
Mita Singh *(D), Ana Teresa Gomes, Moad El-Haddad, Abdel Khalid Saidmeerasah and \\ Rashid Iqbal \\ Department of Cardiology, East Surrey Hospital, Surrey and Sussex Healthcare NHS Trust, \\ Redhill RH1 5RH, UK; AnaTeresa.Gomes@nhs.net (A.T.G.); moad.el-haddad@nhs.net (M.E.-H.); \\ a.saidmeerasah@nhs.net (A.K.S.); rashid.iqbal@nhs.net (R.I.) \\ * Correspondence: mita.singh@nhs.net
}

Received: 29 October 2020; Accepted: 2 November 2020; Published: 4 November 2020

check for updates

\begin{abstract}
Anomalous Left Coronary Artery from the Pulmonary Artery (ALCAPA) is a rare coronary artery anomaly which accounts for $0.25-0.5 \%$ of all congenital cardiac diseases, where most die within the first year of life. We present a case report of a 50-year-old lady who presented to hospital with persistent palpitations. Her admission electrocardiogram found her to be in Atrial Fibrillation (AF). She was rate-controlled and subsequently discharged. Despite that, she represented with further episodes of AF and was referred for an outpatient transthoracic echocardiogram. This revealed a dilated right coronary artery, retrograde flow in the left coronary artery and collateral flow in the myocardium. To investigate, the patient had undergone further imaging which confirmed the diagnosis. As such, she was later shortlisted for surgical intervention. Conclusively, our case exemplifies the role of multimodal imaging to identify the features of ALCAPA and may be useful for the purposes of surgical intervention.
\end{abstract}

Keywords: ALCAPA; adult variant; multimodal imaging; steal phenomenon

\section{Background}

Anomalous Left Coronary Artery from the Pulmonary Artery (ALCAPA), also referred to as Bland-White-Garland syndrome, is a rare coronary artery anomaly which accounts for $0.25-0.5 \%$ of all congenital cardiac diseases and has a reported incidence of 1 in 300,000 live births [1]. Most cases of ALCAPA die in infancy, whereas $10 \%$ survive to adulthood. The adult type of ALCAPA presents with the heightened risk of myocardial ischemia, heart failure and arrhythmia [2], the presentation of which is highlighted in this rare case involving a 50-year-old lady.

\section{Case Presentation}

A 50-year-old Caucasian lady, with a background of migraines, presented to our hospital in October 2014 with persistent palpitations. She reported that her episodes, along with shortness of breath and chest tightness had increased in frequency and severity over the past year. She did not report any chest pain, orthopnoea, paroxysmal nocturnal dyspnoea, presyncope or syncope. There is no known family history of ischaemic cardiac disease but all her siblings suffered from arrhythmias. Other than being an ex-smoker, she did not suffer from diabetes mellitus, hypertension or hypercholesterolaemia and worked as a horse-riding coach. Her admission vital signs were as follows: respiratory rate 18/min, oxygen saturations of 95\% (room air), temperature 36.6 degrees Celsius, blood pressure of 120/63 and pulse 122 (irregular). 
Her admission electrocardiogram showed Atrial Fibrillation (AF) with left axis deviation and partial left bundle branch block (Figure 1). Her admission chest X-ray was normal (Figure 2) and a troponin-T (ng/L) level was also normal $(<13.0)$. She was subsequently reverted to sinus rhythm and an eventual diagnosis of paroxysmal AF was made, managed by beta-blocker and warfarin. The warfarin was subsequently changed to a direct oral anticoagulant. She remained stable until two further episodes of AF in January 2018 and March 2019, chemically cardioverted with flecainide in accident and emergency. She was then referred to cardiology.

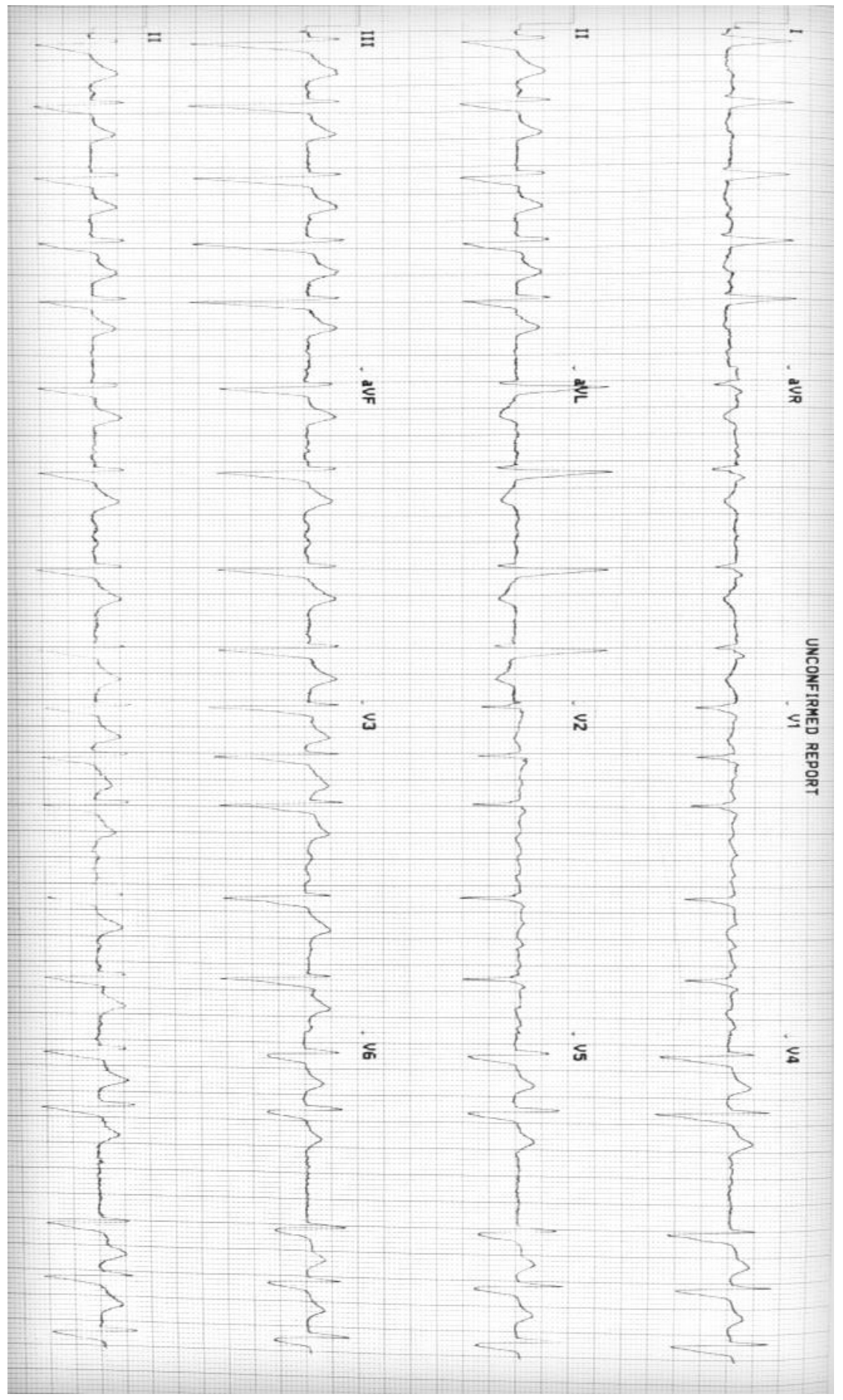

Figure 1. 12-lead electrocardiogram taken on initial admission. It shows atrial fibrillation with a rapid ventricular rate of 122, with evidence of left axis deviation and partial left bundle branch block. 


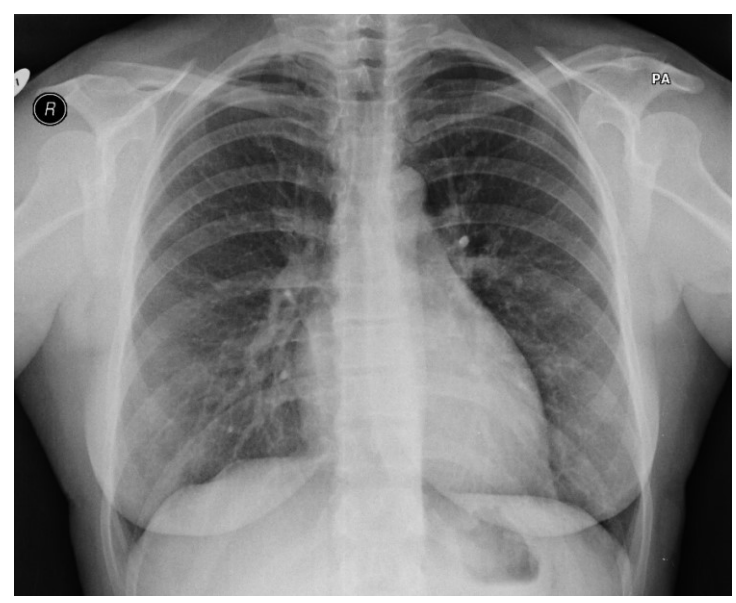

Figure 2. PA chest X-ray taken on initial admission. Lungs were found to be clear with no focal abnormality identified. The heart and mediastinum were reported as normal.

An outpatient transthoracic echocardiogram revealed moderate left ventricular dilatation (and mild dilatation of the right ventricle) with preserved systolic function, severe left atrial dilatation and moderate mitral regurgitation. Furthermore, an anomalous origin of the left coronary artery was also suspected because of the retrograde flow noted in the left anterior descending and left circumflex coronary arteries. A dilated right coronary artery and extensive collateral flow across the myocardium was also visualised (Figure 3).
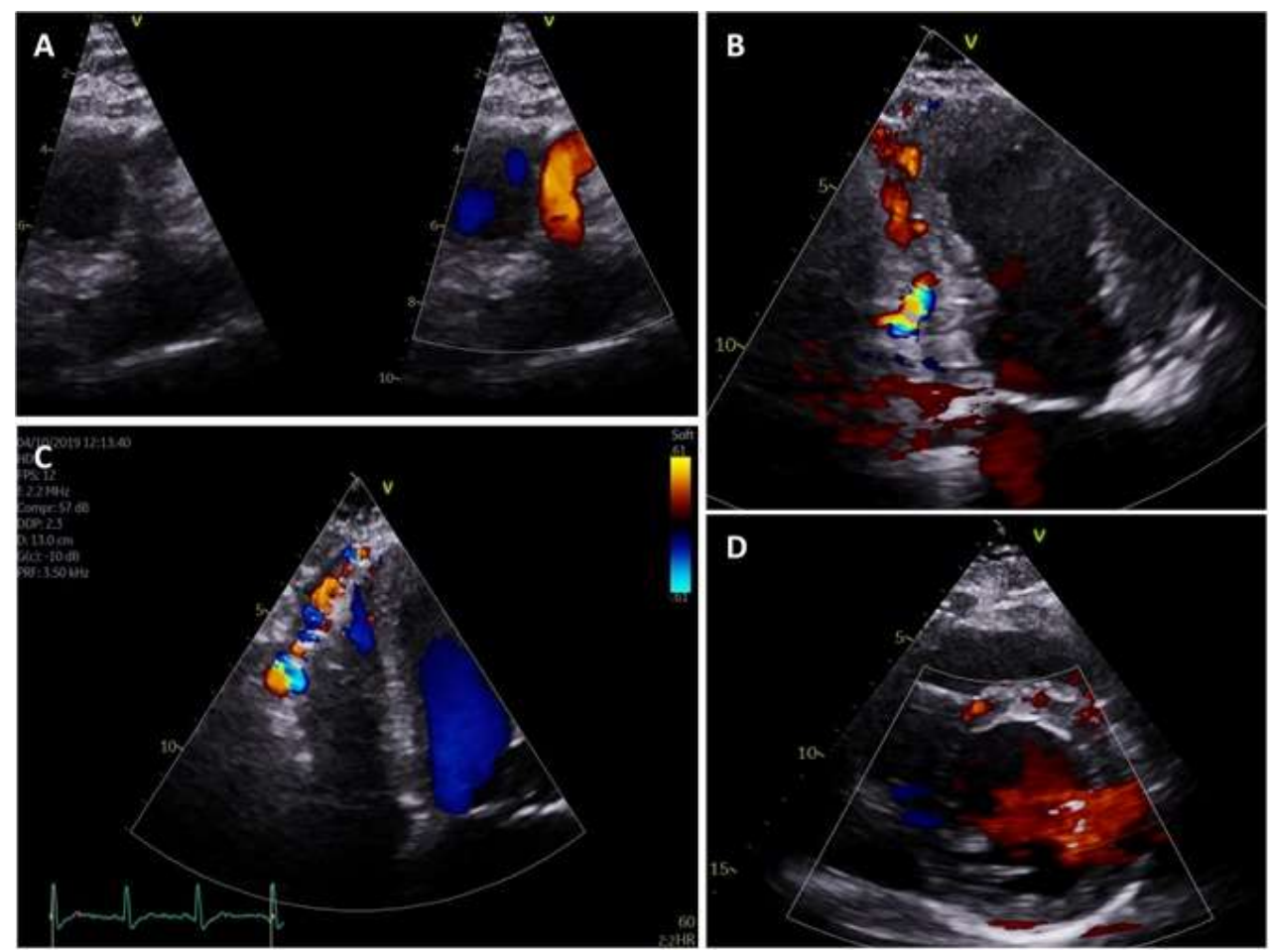

Figure 3. Transthoracic echocardiogram. (A): Modified parasternal long axis view showing a dilated right coronary artery to increase blood supply to the myocardium. (B): Modified apical 2-chamber view focused on the inferior wall showing prominent retrograde coronary flow from the septal perforator coronary arteries. (C): Modified apical 4-chamber view focused on the right ventricle lateral wall showing prominent retrograde coronary flow from the septal perforator coronary arteries extending towards the apex, also known as the "Christmas tree" appearance. (D): Parasternal short axis view at the level of the papillary muscles showing prominent retrograde coronary flow from the septal perforator coronary arteries. 
For further assessment, she underwent cardiac Magnetic Resonance Imaging (MRI) to investigate a possible cardiomyopathy. This showed dilatation of the left ventricle and an ejection fraction of $51 \%$. Late gadolinium enhancement sequences also found a previous myocardial infarction in the LAD territory. In view of the cardiac MRI findings, she had a diagnostic coronary angiogram. This showed a large aneurysmal right coronary artery of normal origin but the left coronary artery could not be cannulated, suggesting an aberrant origin (Figure 4).

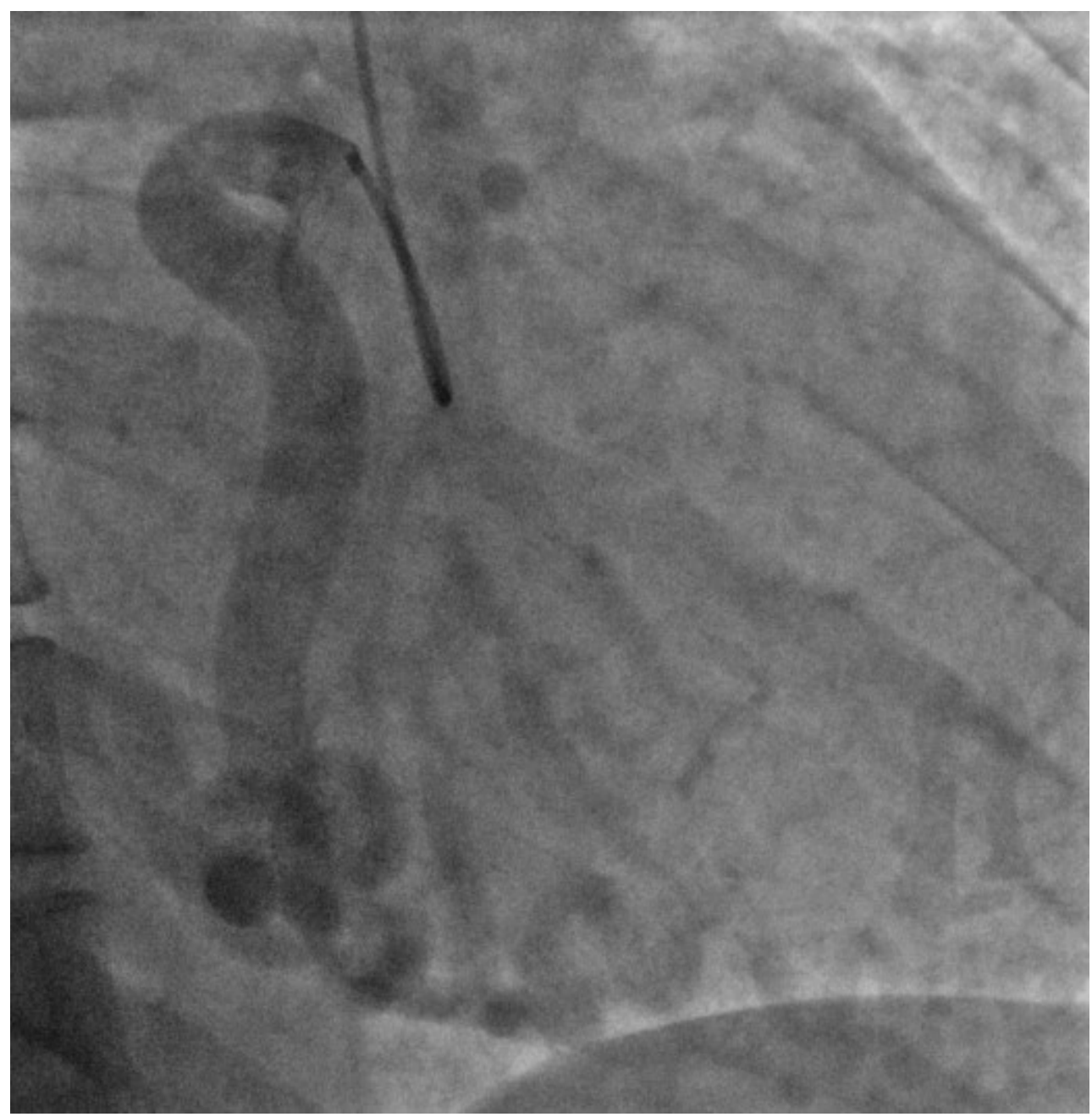

Figure 4. Angiographic image of the coronary circulation and collaterals. Right coronary artery appears dilated and tortuous with collaterals following across to the left side of the heart.

In order to delineate the origin of the left coronary artery, a Computer Tomography Coronary Angiogram (CTCA) was later performed and illustrated that both arteries were diffusely aneurysmal. Whilst the right coronary artery originated from the right coronary sinus, the left coronary artery anomalously originated from the left anterior pulmonary sinus of the main pulmonary artery (Figure 5). Furthermore, there was a right dominant coronary artery system with multiple collateral vessels (also visualised on the coronary angiogram) and no evidence of coronary artery stenosis. This suggested a diagnosis of ALCAPA. 

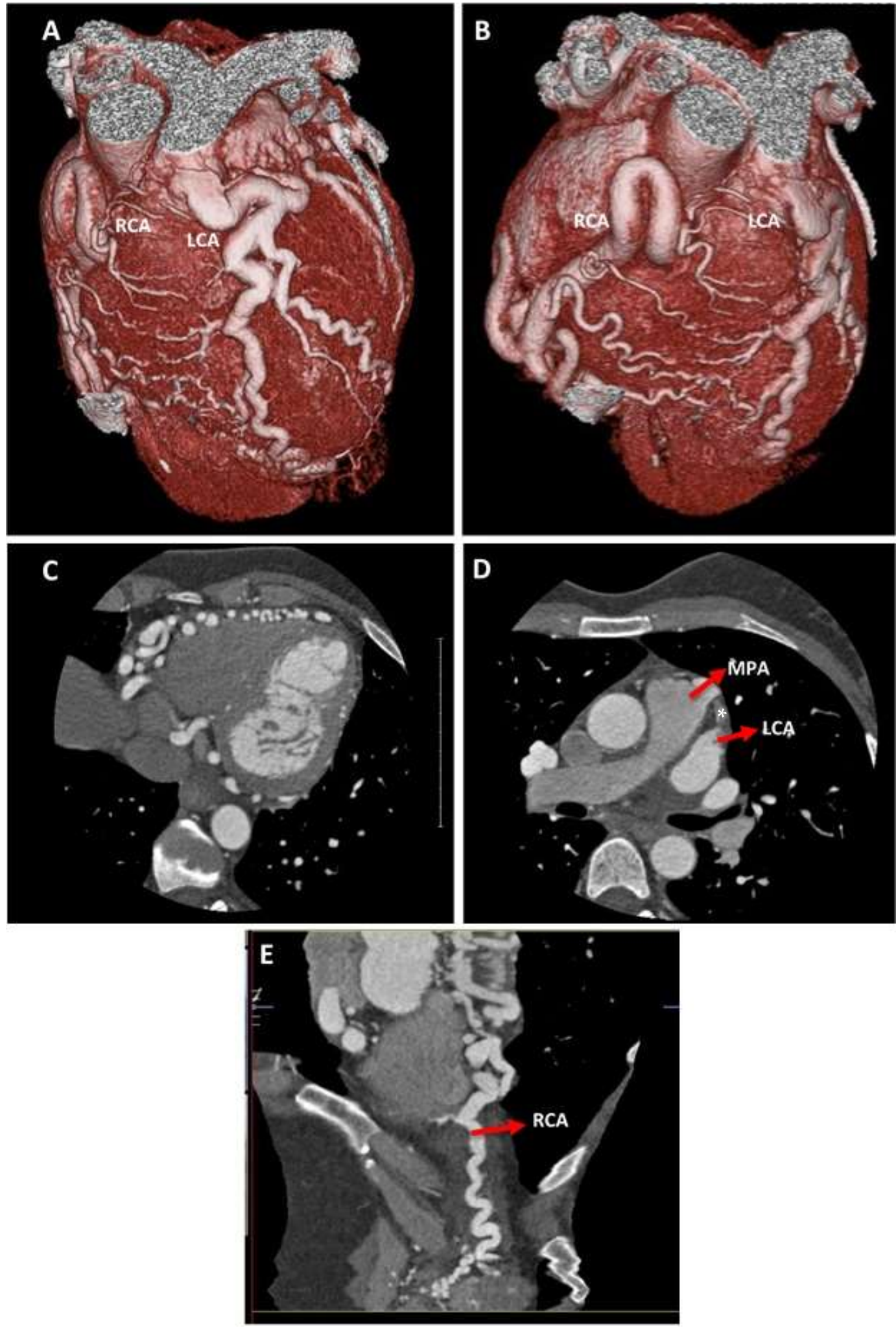

Figure 5. Computer tomography coronary angiogram (CTCA) with contrast. Heart rate control and coronary vasodilatation was achieved using an oral beta-blocker and sublingual glyceryl trinitrate spray, respectively. The right coronary artery (RCA) appears diffusely dilated and has a normal origin from the right coronary sinus. The left coronary artery (LCA) has an anomalous origin from the main pulmonary artery (MPA). There is a right dominant coronary artery system, where multiple collaterals arise from the RCA, spanning towards the LCA. The left main stem (LMS) is also dilated and divides 
into the left anterior descending artery (LAD) and the left circumflex artery (LCx). Both RCA and LCA, with the collaterals, appear tortuous. There is no evidence of coronary artery calcification. In summary, CTCA with contrast confirms that there is an anomalous origin of the left coronary artery from the main pulmonary artery (ALCAPA). (A,B) Volume rendering demonstrating anomalous origin of the LCA from the MPA and marked dilatation and tortuosity of the coronary arteries. Collaterals between RCA and LCA are also seen. (C) Axial view demonstrating the marked tortuosity of the RCA. (D) Axial view of the origin of LCA from MPA $\left(^{*}\right)$. (E) Multiplanar reconstruction demonstrating a dilated and tortuous RCA.

\section{Outcome and Follow-Up}

She was referred for surgical intervention following a joint cardiology and cardiothoracic surgery team discussion.

\section{Discussion}

This case report describes a 50-year-old lady who presented with AF and was incidentally found to have myocardial ischaemia and early stages of heart failure, all of which a likely consequence of ALCAPA syndrome.

This extremely rare congenital anomaly was first clinically described by Bland, White and Garland in 1933 [3]. As previously discussed, there are two variants of ALCAPA syndrome: infant and adult type. Prior to birth, the ductus arteriosus equalises the systemic and pulmonary arterial circulations, ensuring antegrade blood flow. After birth, however, the ductus arteriosus is physiologically occluded and, because of the decreased pulmonary pressure, the flow in the left coronary artery also decreases-so much that it reverses [4]. This is known as the steal phenomenon, whereby blood is carried away from the myocardium and towards the pulmonary artery. In the adult type of ALCAPA, inter-coronary collaterals form to compensate for the lack of blood supply [5]. The extent of compensation through these collaterals determines the extent of myocardial ischemia and mitral insufficiency [4,5]. In our case, extensive inter-coronary collaterals were found via CTCA and diagnostic coronary angiography, possibly explaining why few complications were found. It might also justify why $15 \%$ of patients who do not undergo surgical intervention survive childhood [6].

Despite that, this might be an underestimation and the true incidence of this rare congenital anomaly is thought to be higher with the increasing use of multimodal imaging. CTCA is considered the radiographic modality of choice for diagnosing ALCAPA [7]. With the help of three-dimensional reconstruction, CTCA can narrate the course and location of arteries which assists with planning for coronary reimplantation [8]. In addition, a dilated right coronary artery and inter-coronary collaterals may be visualised better by CTCA compared to cardiac MRI. In contrast, cardiac MRI may provide better functional evaluation and can elicit the steal phenomenon $[9,10]$. Myocardial infarcts (via late gadolinium enhancement sequences), mitral valve insufficiency and left ventricular dilatation are better detected by cardiac MRI — additional features of ALCAPA [9]. Furthermore, diagnostic coronary angiography can provide more accurate quantifications than CTCA and possesses the ability for possible intervention (but is associated with low procedural complications) [11].

Transthoracic echocardiography tends to be the first imaging modality in most clinical scenarios, and, as evident in our case, can be used to suspect ALCAPA. Some of the reported echocardiographic features of ALCAPA include [12], mitral regurgitation, retrograde flow in the left coronary artery, dilated right coronary artery, collateral flow in the myocardium and an aberrant origin of the left main stem (Figure 3). This justifies the role of transthoracic echocardiography, a readily available and inexpensive tool that may uncover features of ALCAPA early on. 


\section{Conclusions}

Here, we present a case of ALCAPA syndrome of the adult variant, incidentally found in a middle-aged lady. Features of ALCAPA were first discovered using transthoracic echocardiography, a relatively inexpensive, non-invasive and readily available diagnostic imaging modality. We later confirmed our diagnosis using other imaging modalities, whilst excluding other potential differentials. Our case report supports the role of multimodal imaging where transthoracic echocardiography may suspect ALCAPA before the use of CTCA, cardiac MRI and diagnostic coronary angiography which may together plan for coronary reimplantation or other forms of surgical interventions.

Author Contributions: M.S.: Leading the case report, writing the manuscript/paper (introduction, case presentation, follow up, discussion and conclusion) and constructing a team to complete the report. They were also responsible for composing figures for the report and gaining signed consent. A.T.G.: Assisted with selecting and interpreting echocardiogram images and provided captions. They also captioned the selected videos and helped review the written manuscript. M.E.-H.: Offered advice and jointly-assisted with retrieval of angiogram still image. A.K.S.: Selecting and interpreting cardiac MRI images. They also selected videos for the case report and reviewed the written manuscript. R.I.: Played an advisory role and reviewed the written manuscript. All authors have read and agreed to the published version of the manuscript.

Funding: This research received no external funding.

Conflicts of Interest: The authors declare that there is no conflict of interest regarding the publication of this case report.

\section{References}

1. Weerakkody, Y. Anomalous Left Coronary Artery from the Pulmonary Artery. Radiopaedia. Available online: https://radiopaedia.org/articles/anomalous-left-coronary-artery-from-the-pulmonary-artery?lang= gb (accessed on 11 June 2020).

2. Kim, S.Y.; Seo, J.B.; Do, K.H.; Heo, J.N.; Lee, J.S.; Song, J.W.; Choe, Y.H.; Kim, T.H.; Yong, H.S.; Choi, S.I.; et al. Coronary Artery Anomalies: Classification and ECG-gated Multi-Detector Row CT Findings with Angiographic Correlation. RadioGraphics 2006, 26, 317-333. [CrossRef] [PubMed]

3. Bland, E.F.; White, P.D.; Garland, J. Congenital anomalies of the coronary arteries: Report of an unusual case associated with cardiac hypertrophy. Am. Heart J. 1933, 8, 787-801. [CrossRef]

4. Vizzuso, A.; Righi, R.; Zerbini, M.; Gamanji, S.; Cucchi, P.; Gallo, F.; Giganti, M.; Benea, G.; Carnevale, A. An unusual presentation of anomalous left coronary artery from the pulmonary artery (ALCAPA) syndrome in a 70-year-old man: A case report. J. Med. Case Rep. 2018, 12, 1-7. [CrossRef] [PubMed]

5. Shriki, J.E.; Shinbane, J.S.; Rashid, M.A.; Hindoyan, A.; Withey, J.G.; DeFrance, A.; Cunningham, M.; Oliveira, G.R.; Warren, B.H.; Wilcox, A. Identifying, characterizing, and classifying congenital anomalies of the coronary arteries. Radiographics 2012, 32, 453-468. [CrossRef] [PubMed]

6. Fierens, C.; Budts, W.; Denef, B.; Werf, F. A 72 year old woman with ALCAPA. Heart Br. Card. Soc. 2000, 83, E2. [CrossRef] [PubMed]

7. Schmitt, R.; Froehner, S.; Brunn, J.; Wagner, M.; Brunner, H.; Cherevatyy, O.; Gietzen, F.; Christopoulos, G.; Kerber, S.; Fellner, F. Congenital anomalies of the coronary arteries: Imaging with contrast-enhanced, multidetector computed tomography. Eur. Radiol. 2005, 15, 1110-1121. [CrossRef] [PubMed]

8. John, J.; Miller, J.H.; Leslie, S.J. A Case of Anomalous Coronary Artery Origin: The Role of Computerised Tomography. SAGE Open Med. Case Rep. 2016, 4. Available online: https://www.ncbi.nlm.nih.gov/pmc/ articles/PMC4927289/ (accessed on 11 June 2020). [CrossRef] [PubMed]

9. Heermann, P.; Heindel, W.; Schülke, C. Coronary Artery Anomalies: Diagnosis and Classification based on Cardiac CT and MRI (CMR)_From ALCAPA to Anomalies of Termination. Rofo 2017, 189, 29-38. [PubMed]

10. Zacharias, M.; Chandok, D.; Tighe, D. A late presentation of an anomalous left coronary artery originating from the pulmonary artery (ALCAPA): A case study and review of the literature. J. Cardiol. Cases 2015, 11, 56-59. [CrossRef] [PubMed] 
11. Oncel, G.; Oncel, D. Anomalous Origin of the Left Coronary Artery from the Pulmonary Artery: Diagnosis with CT Angiography. J. Clin. Imaging Sci. 2013, 3, 4. Available online: https://www.ncbi.nlm.nih.gov/pmc/ articles/PMC3625882/ (accessed on 12 June 2020). [CrossRef]

12. Saedi, S.; Parsaee, M.; Farrashi, M.; Noohi, F.; Mohebbi, B. The role of echocardiography in anomalous origin of coronary artery from pulmonary artery (ALCAPA): Simple tool for a complex diagnosis. Echocardiography 2019, 36, 177-181. [CrossRef] [PubMed]

Publisher's Note: MDPI stays neutral with regard to jurisdictional claims in published maps and institutional affiliations.

(C) 2020 by the authors. Licensee MDPI, Basel, Switzerland. This article is an open access article distributed under the terms and conditions of the Creative Commons Attribution (CC BY) license (http://creativecommons.org/licenses/by/4.0/). 